\title{
CARBON SEQUESTERED, CARBON DISPLACED AND THE KYOTO CONTEXT
}

Gregg Marland and Bernhard Schlamadinger

Environmental Sciences Division

Oak Ridge National Laboratory, Oak Ridge, TN, 37831-6335, USA

Phone: +1/423/241-4850, Fax: +1/423/574-2232, e-mail: gum@oml.gov

\begin{abstract}
The integrated system that embraces forest management, forest products, and land-use change impacts the global carbon cycle - and hence the net emission of the greenhouse gas carbon dioxide - in four fundamental ways. Carbon is stored in living and dead biomass, carbon is stored in wood products and landfills, forest products substitute in the market place for products made from other materials, and forest harvests can be used wholly or partially to displace fossil fuels in the energy sector. Implementation of the Kyoto Protocol to the United Nations Framework Convention on Climate Change would result in the creation of international markets for carbon dioxide emissions credits, but the current Kyoto text does not treat all carbon identically. We have developed a carbon accounting model, GORCAM, to examine a variety of scenarios for land management and the production of forest products. In this paper we explore, for two simple scenarios of forest management, the carbon flows that occur and how these might be accounted for under the Kyoto text. The Kyoto protocol raises questions about what activities can result in emissions credits, which carbon reservoirs will be counted, who will receive the credits, and how much credit will be available? The Kyoto Protocol would sometimes give credits for carbon sequestered, but it would always give credits when fossil-fuel carbon dioxide emissions are displaced.
\end{abstract}

If a forest grows on land not previously in forest, carbon will accumulate in the growing biomass and there will he a decreased accumulation of the greenhouse gas carbon dioxide in the Earth's atmosphere. This is a common vision of how afforestation can be used to mitigate the accumulation of carbon dioxide in the atmosphere and the potential importance of carbon sinks is acknowledged in The Kyoto protocol to the United Nations Framework Convention on Climate Change [I]. If ratified, the Kyoto Protocol would permit the country responsible for afforestation to use the accumulating carbon as a credit against it's commitments to reduce greenhouse gas emissions - if the afforestation occurred since 1990 and the change in carbon stocks is reported in a "transparent and verifiable manner". Although the Kyoto Protocol is not explicit, we expect that this offset credit should include all carbon stocks in the forest, including the carbon in the forest soil.

In Figure 1 we use the output from our carbon accounting model to illustrate the accumulating carbon credits for a simple afforestation scenario. The figure shows that over time carbon will accumulate in the forest stand, including in the forest soil and forest litter, but that eventually trees approach maturity and the stand is unable to accumulate additional carbon. It approaches a steady-state carbon stock.

\footnotetext{
"The submitted manuscript has been authorized by a contractor The U. Government under contract No. DE-ACOSAccordingly, the US Government retains a non$960 R 22464$. Accordingly, the U.S. Gover ment retaice the exclusive, royalty-free license to publish or reproduce the published form of this contribution for U.S. Government purposes."
} 


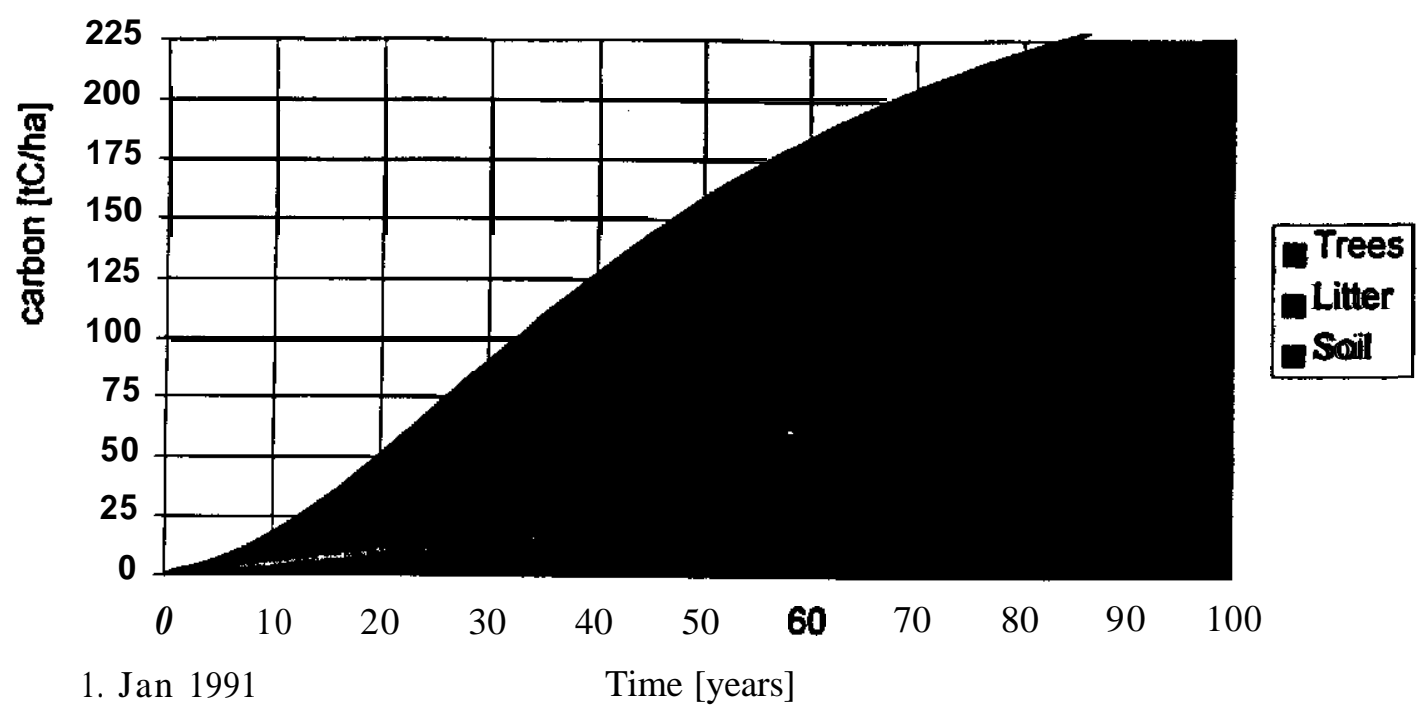

Figure 1: Cumulative carbon-stock changes for an afforestation scenario.

There are, of course, many land-use and forest management practices that could impact the net emission of carbon dioxide to the atmosphere. Our focus here is on analyzing these impacts and on the way in which changes in carbon stocks will be measured, monitored, and credited in international efforts to "prevent dangerous anthropogenic interference with the climate system" [2]. The model GoRCAM (Graz/Oak Ridge Carbon Accounting Model) has been developed to try to examine the full system that is impacted by forest management decisions and to illustrate the effect that these decisions have on net carbon dioxide emissions. Protection of a growing forest stand, for example, can not only prevent the emission of its carbon stocks to the atmosphere, but can permit continuing accumulation of carbon from the atmosphere until the stand approaches maturity. If the same stand is harvested to produce a conventional mix of forest products, there will be an initial loss of carbon in the forest, but there will be an increase in carbon in forest products and an increase in the substitution of forest products and bioenergy for other products and other sources of energy. (This is under the assumption that increased harvest is coupled with an increased demand for wood products).

In Figure 2, output from GORCAM illustrates the net impact on atmospheric $\mathrm{CO}_{2}$ if the forest stand from Figure 1 is harvested after $\mathbf{4 0}$ years and the harvest is used for a conventionial mix of forest products. The numeric details of Figure 2 depend on the exact values for many input parameters in the model so the diagram presented here should be taken to illustrate the nature of the flows rather than to demonstrate their values. Nonetheless, the figure shows that when the forest is harvested carbon is sequestered in harvested materials (including, eventually, landfills) and that harvested materials substitute for other products that are generally more energy intensive to produce. Details of GORCAM can be found in Schlamadinger and Marland [3] and a sensitivity analysis of the importance of some of the principal model parameters is in Marland and Schlamadinger [4]. Whereas the carbon lo the protected forest stand of Figure 1 can be expected to approach some steady state value over time, the carbon displacement of Figure 2 can be expected to continue to increase over time. Note that the expected carbon sequestration after 50 years amounts to $128 \mathrm{tC} / \mathrm{ha}$. 


\title{
CARBON SEQUESTERED, CARBON DISPLACED AND THE KYOTO CONTEXT
}

\author{
Gregg Marland and Bernhard Schlamadinger \\ Environmental Sciences Division \\ Oak Ridge National Laboratory, Oak Ridge, TN, 3783 I-6335, USA \\ Phone: +1/423/241-4850, Fax: +1/423/574-2232, e-mail: gum@oml.gov
}

\begin{abstract}
The integrated system that embraces forest management, forest products, and land-use change impacts the global carbon cycle - and hence the net emission of the greenhouse gas carbon dioxide - in four fundamental ways. Carbon is stored in living and dead biomass, carbon is stored in wood products and landfills, forest products substitute in the market place for products made from other materials, and forest harvests CM be used wholly or partially to displace fossil fuels in the energy sector. Implementation of the Kyoto Protocol to the United Nations Framework Convention on Climate Change would result in the creation of international markets for carbon dioxide emissions credits, but the current Kyoto text does not treat all carbon identically. We have developed a carbon accounting model, GORCAM, to examine a variety of scenarios for land management and the production of forest products. In this paper we explore, for two simple scenarios of forest management, the carbon flows that occur and how these might be accounted for under the Kyoto text. The Kyoto Protocol raises questions about what activities can result in emissions credits, which carbon reservoirs will be counted, who will receive the credits, and bow much credit will be available? The Kyoto Protocol would sometimes give credits for carbon sequestered, but it would always give credits when fossil-fuel carbon dioxide emissions are displaced.
\end{abstract}

If a forest grows on land not previously in forest, carbon will accumulate in tbe growing biomass and there will be a decreased accumulation of the greenhouse gas carbon dioxide in the Earth's atmosphere. This is a common vision of how afforestation can be used to mitigate the accumulation of carbon dioxide in the atmosphere and the potential importance of carbon sinks is acknowledged in The Kyoto Protocol to the United Nations Framework Convention on Climate Change [1]. If ratified, the Kyoto Protocol would permit the country responsible for afforestation to use the accumulating carbon as a credit against it's commitments to reduce greenhouse gas emissions - if the afforestation occurred since 1990 and the change in carbon stocks is reported in a "transparent and verifiable manner". Although the Kyoto Protocol is not explicit, we expect that this offset credit should include all carbon stocks. in the forest, including the carbon in the forest soil.

In Figure 1 we use the output from our carbon accounting model to illustrate the accumulating carbon credits for a simple afforestation scenario. The figure shows that over time carbon will accumulate in the forest stand, including in the forest soil and forest litter, but that eventually trees approach maturity and the stand is unable to accumulate additional carbon. It approaches a steady-state carbon stock.

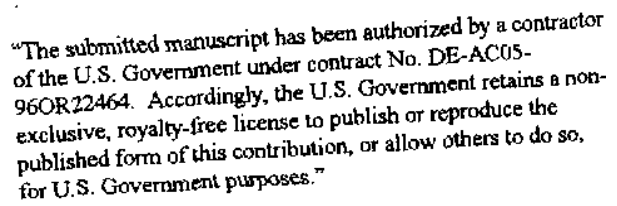




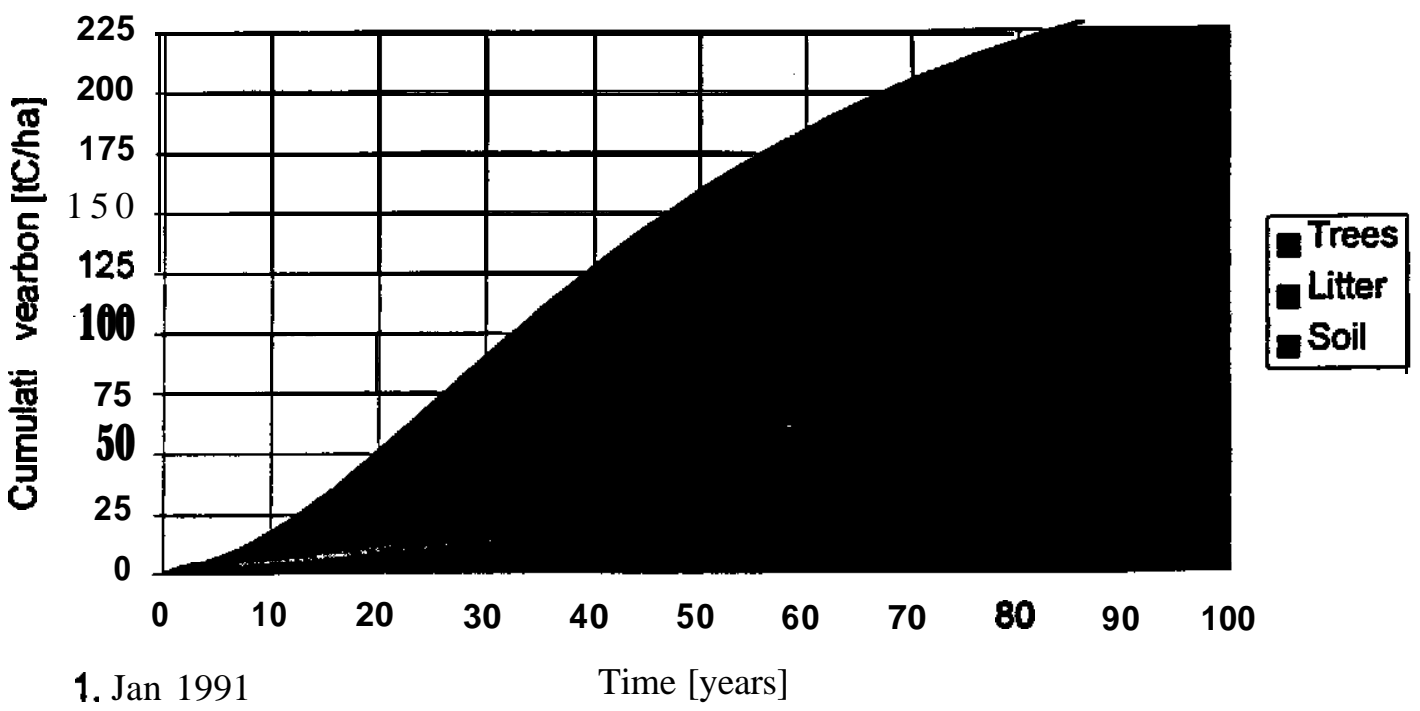

Figure I: Cumulative carbon-stock changes for an afforestation scenario.

There are, of course, many land-use and forest management practices that could impact the net emission of carbon dioxide to the atmosphere. Our focus hem is on analyzing these impacts and on the way in which changes in carbon stocks will be measured, monitored, and credited in international efforts to "prevent dangerous anthropogenic interference with the climate system" [2]. The model GORCAM (Graz/Oak Ridge Carbon Accounting Model) has been developed to try to examine the full system that is impacted by forest management decisions and to illustrate the effect that these decisions have on net carbon dioxide emissions. Protection of a growing forest stand, for example, can not only prevent the emission of its carbon stocks to the atmosphere, but can permit continuing accumulation of carbon from the atmosphere until the stand approaches maturity. If the same stand is harvested to produce a conventional mix of forest products, there will be an initial loss of carbon in the forest, but there will be an increase in carbon in forest products and an increase in the substitution of forest products and bioenergy for other products and other sources of energy. (This is under the assumption that increased harvest is coupled with an Increased demand for wood products).

In Figure 2, output from GORCAM illustrates the net impact on atmospheric $\mathrm{CO}_{2}$ if the forest stand from Figure 1 is harvested after 40 years and the harvest is used for a conventional mix of forest pmducts. The numeric details of Figure 2 depend on the exact values for many input parameters in the model so the diagram presented here should be taken to illustrate the nature of the flows rather than to demonstrate their values. Nonetheless, the figure shows that when the forest is harvested carbon is sequestered in harvested materials (including, eventually, landfills) and that harvested materials substitute for other products that are generally more energy intensive to produce. Details of GORCAM can be found in Schlamadinger and Marland [3] and a sensitivity analysis of the importance of some of the principal model parameters is in Marland and Schlamadmger [4]. Whereas the carbon in the protected forest stand of Figure 1 can be expected to approach some steady state value over time, the carbon displacement of Figure 2 can be expected to continue to increase over time. Note that tbe expected carbon sequestration after $\mathbf{5 0}$ years amounts to $128 \mathrm{tC} / \mathrm{ha}$. 


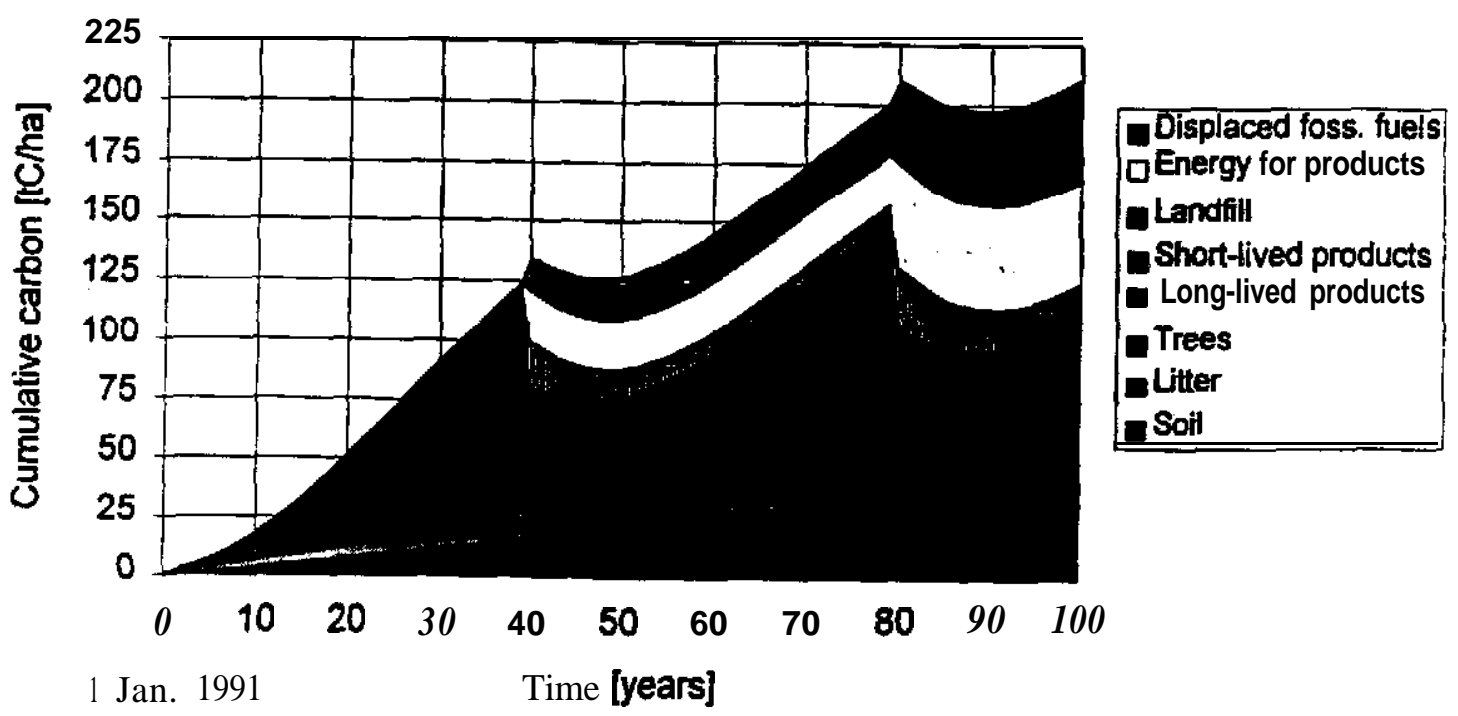

Figure 2: Cumulative carbon-stock changes for a scenario involving afforestatand harvest. These are net changes in that, for example, the diagram shows savings in fossil fuel emssions with respect to an alternate scenario that uses fossil fuels and alternative, more energy-intensive products to provide the same services.

On a global scale, the relative merits of forest protection versus forest harvest (ii terms of net carbon dioxide emissions to the atmosphere) will depend importantly on the status of the forest at the beginning of the accounting, the forest productivity, the efficiency with which forest products are produced and used, and on out perception of how time and uncertainty should be treated [4].

These two figures display the principal impacts that the respective scenarios would have on the global carbon budget, but they raise challenging questions in the context of the Kyoto Protocol. The Kyoto Protocol specifically establishes in Article 3.3 that credits or debits can be obtained for afforestation, reforestation, and deforestation since 1990. That is, the carbon accumulated in the scenario of Figure 1 could be used to meet national commitments whereas there is continuing uncertainty about how the carbon stock changes represented in Figure $\mathbf{2}$ might be counted. (It is, for example, not yet established how harvesting of forests planted since 1990 should be accounted for. If a forest stand is planted after 1990 and subsequently harvested during a commitment period, should the stock change toward a lower level show up in the accounting?).

Two points should be made about Figure I. First, the Kyoto Protocol is not absolutely clear which stocks are to be included as part of the forest The carbon in above ground biomass is surely to be counted. Our feeling is that the carbon in forest soils and litter is equally a part of the forest but there is continuing discussion about whether this will be generally accepted. The decision will likely hinge on the requirement that increases in carbon stocks be measured in a reliable and verifiable manner. Second, the Kyoto Protocol provides that developed countries (listed in its Annex B) can pursue activities in non-Annex B countries and use the emissions reduction credits in the accounts of the Annex B country. This text in Article 12 does not clearly establish whether or not carbon sinks in non-Annex B countries can be used, similarly to the emissions reductions, in the accounts of the Annex B partner.

The issues raised concern both what activities can produce carbon credits for increasing carbon storage in sinks and what carbon pools will be counted. Whereas Article 3.3 of the'Kyoto protocol limits credits to afforestation, reforestation, and deforestation, Article 3.4 of the Protocol leaves open the opportunity to add additional activities. The Protocol does not specifically mention forest soils or forest products but these could be embraced by appropriate consensus on interpretation of the current text (see, e.g., Schlamadinger and Marland, [5]). 
Another challenge of the Kyoto Protocol has to do with the way in which carbon credits accrue. The Protocol, and subsequent decisions of the Congress of Parties to the Framework Convention, establish that emissions or sinks in the biosphere will be measured as tbe changes in carbon stocks-exactly as illustrated in the GORCAM diagrams above. Given this dictate, the change in carbon stocks for the landowner who is host of the forest management project illustrated in Figure 2 is as shown in Figure 3. The point of comparing these two figures is that fossil fuel displacement and carbon accumulation in Forest products are real but they likely do not occur in the accounts of the forest manager. The decreases in Fossil fuel usage will always count toward compliance with Kyoto commitments, but not likely in the accounts of the Forest manager. Changes in carbon stocks in the forest will count in the commitments of the forest manager if they meet the requirements of Article 33. For projects that concentrate on the Forest carbon stocks it is hard to establish whether the harvested wood will increase tbe total market volume, or whether it will simply displace wood from another source. This distribution of credits will presumably be captured in the accounts of countries or large, multi-Faceted companies or projects; but it will be bard to capture at tbe level of many carbon dioxide mitigation projects. For projects that arc able to create new demand (for example, a woodfuel plantation adiacent to a new biomass nower plant) the substitution effects will occur within the bounds of the project, and will be easier to account For. .

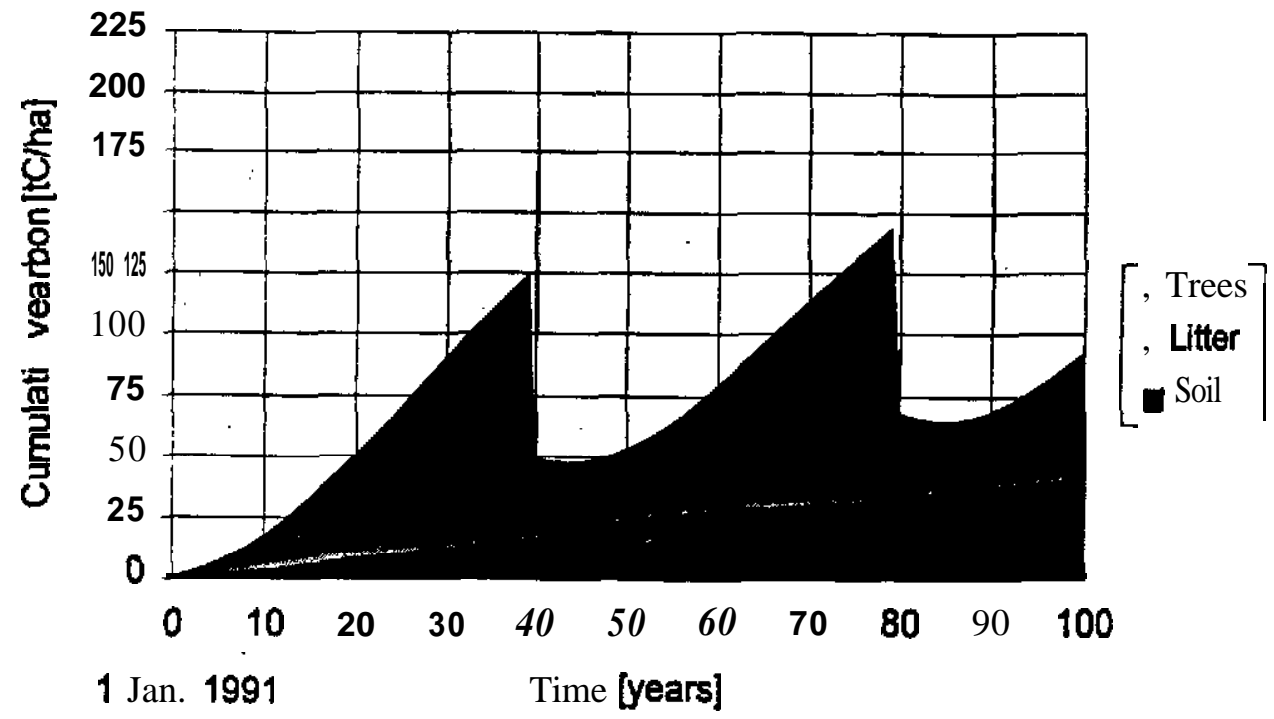

Figure 3: As in Figure 2, but only the carbon-stock changes in the account of the land owner arc shown.

Another intriguing question raised by the Kyoto Protocol has to do with the magnitude of credits generated by carbon sinks. Many negotiators had considerable misgiving about including credit For carbon sinks in the Protocol and this was partly due to concern that the stored carbon could be measured and verified accurately. The possibility has been raised of discounting carbon sinks to accommodate the uncertainty of measurement. A proposal by Canada [6], For example, would establish that credits For sinks require that there be $95 \%$ confidence that the credit was indeed accomplished. Figures 4, 5, 6, and 7 illustrate how rhis might affect carbon credits. WC have taken the scenario of Figure 2 and substituted probability distribution functions in place of discrete values for some of the principal parameters. The result is a probability distribution of potential outcomes. This probability distribution describes the range of possible outcomes, but can also be visualized as the result of the uncertainties in measurement of some parameters and hence as the uncertainty of measured outcomes.

To create Figures 4 and 5, we carried out 250 GORCAM model runs, with each model run using a random number generator to generate a variety of the key input parameters defined by probability distributions (see Note 1 for \&ails). Figure 4 shows the total net sequestration of carbon and this corresponds to the upper bound of Figure 2. Figure S depicts the probability distribution for the carbon sequestration outcomes after 50 years (this is a cross section of the distribution in Figure 4 at time 50). The 5\% percentile, mean, and 
95\% percentile values in Figure $\mathbf{5}$ arc at 99. 132, and 171 tCha after 50 years. In other words, in order to achieve the carbon benefits predicted in Figure $2(128 \mathrm{tC})$ with a certainty of $95 \%$, and witb the probability distributions assumed For various input parameters, the project area would have to be increased from $\mathbf{l}$ ha to 1.29 ha (128 divided by 99). Conversely, the project envisioned in Figure 2 would generate 128 tCha credit if all of the values were perfectly known but only $99 \mathrm{tC} / \mathrm{ha}$ with the uncertain\&s assumed here and the requirement that the goal be fulfilled with $95 \%$ probability.

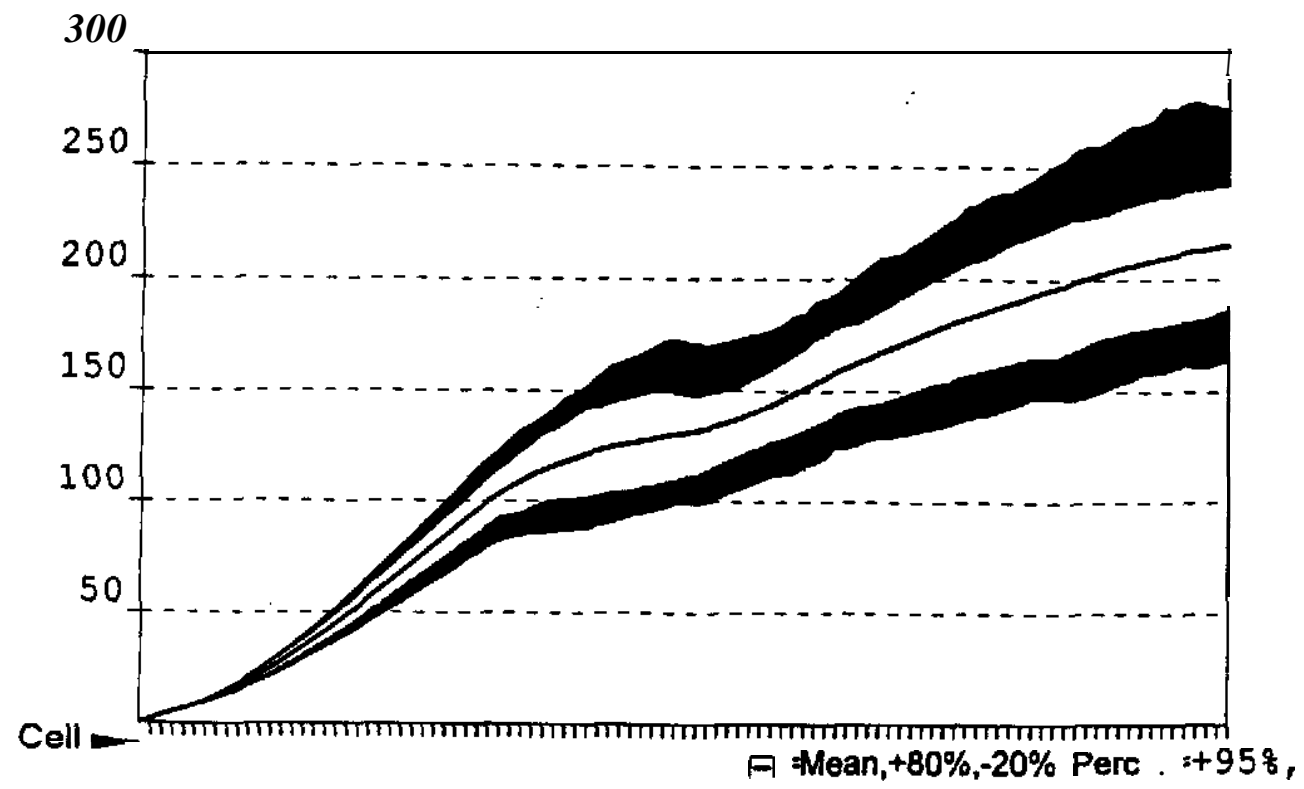

Time [years] from 0 to 100

Figure 4: Cumulative carbon sequestration as in Figure 2. but with probability distributions applied to various input parameters of the GORCAM model. The line in the center of the white area represents the most likely outcome, whereas the bounds of the white area arc the 20 and $80 \%$ percentiles. The outer bounds of the dark areas are the 5 and $95 \%$ percentiles.

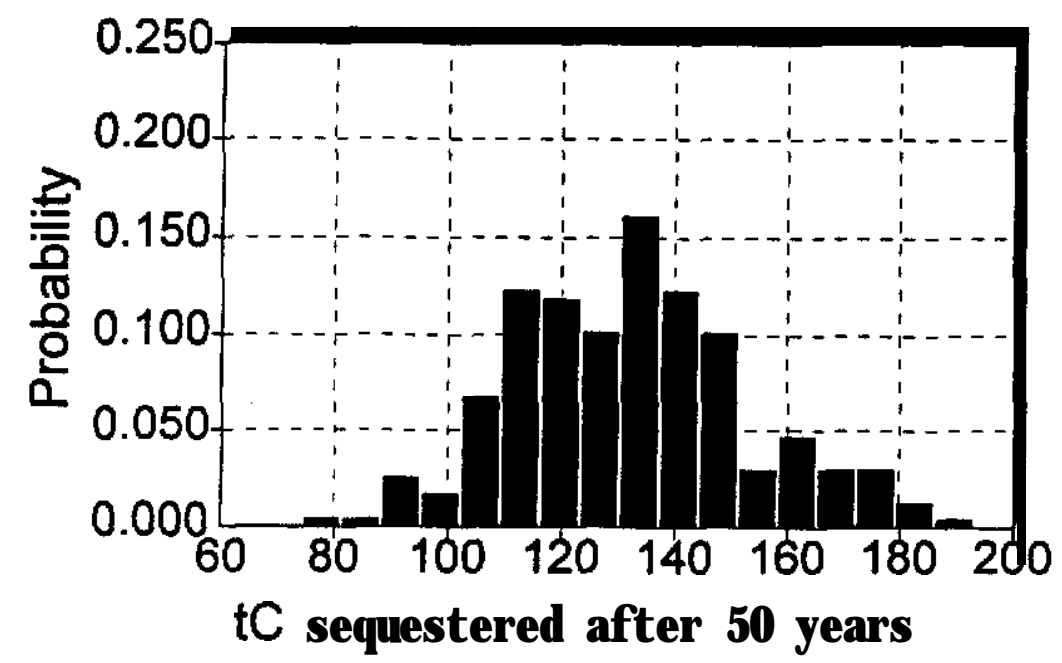

Figure 5: Cross section of the probability distribution in Figure 4, at time $=50$ years 
Figures 6 and 7 are exactly as in Figures 4 and 5 except that the deviations from the mean for the various input parameters are only half as large, i.e. the uncertainties of the $\mathbf{I}$ nput parameters are smaller. It can be seen that the bands for the 20/80 and 5/95 percentiles arc narrower in Figure 6 than in Figure 4. A cross section of Figure 6 is provided in Figure 7. Figures 6 and 7 show that this case, with smaller uncertainty in the input parameters, will provide more credits that fulfill the $95 \%$-certainty threshold. The $5 \%$ percentile, mean, and $95 \%$ percentile are now at 112,128 , and $145 \mathrm{tC} / \mathrm{ha}$. The project of Figure 2 could provide credits of $112 \mathrm{t} \mathrm{C} / \mathrm{ha}$ with $95 \%$ certainty and the probability distributions assumed in the calculations for Figures 6 and 7 . In other words, the area required area to provide $128 \mathrm{tC}$ of credits, which was I ba in the case with zero uncertainty, and 1.29 ha in the case with high uncertainty, is now at I. I3 ha with low uncertainty.

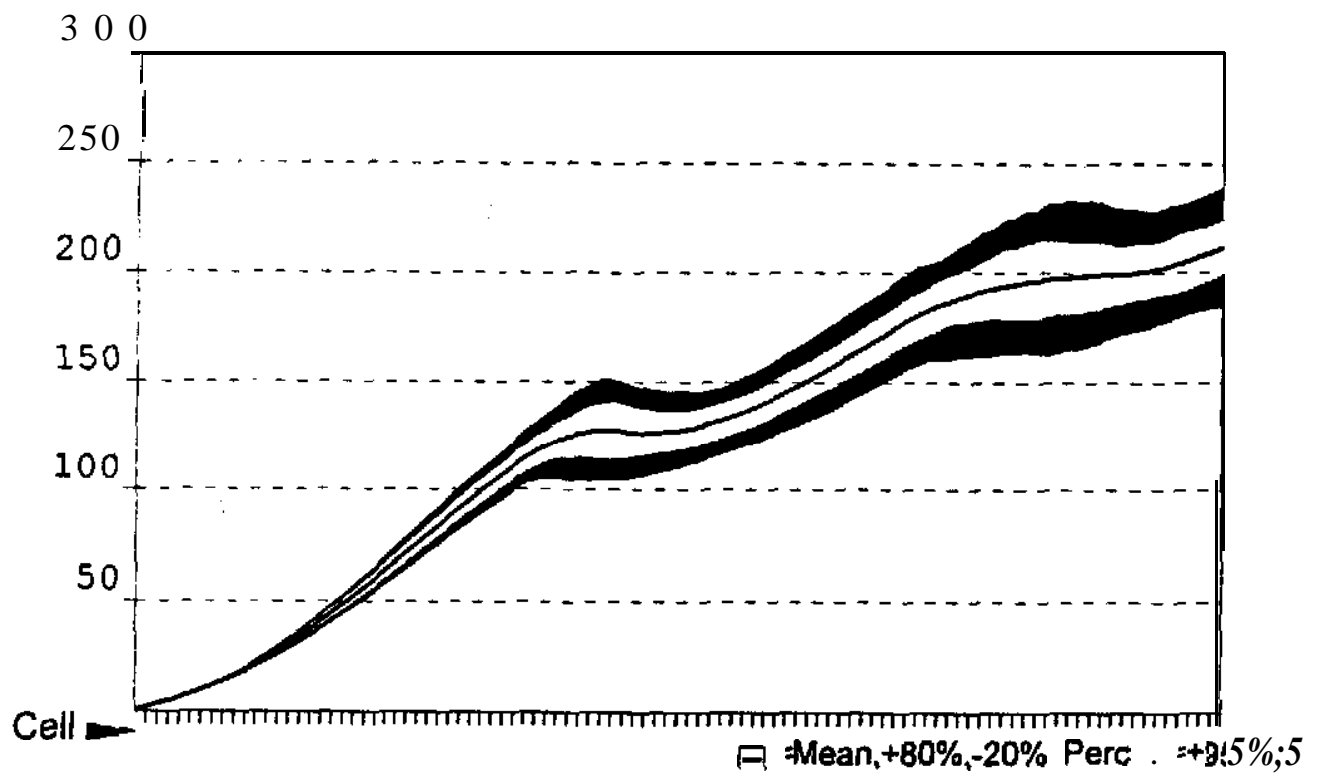

Time [years] from 0 to 100

Figure 6: As in Figure 4, but with a smaller uncertainty of input parameters.

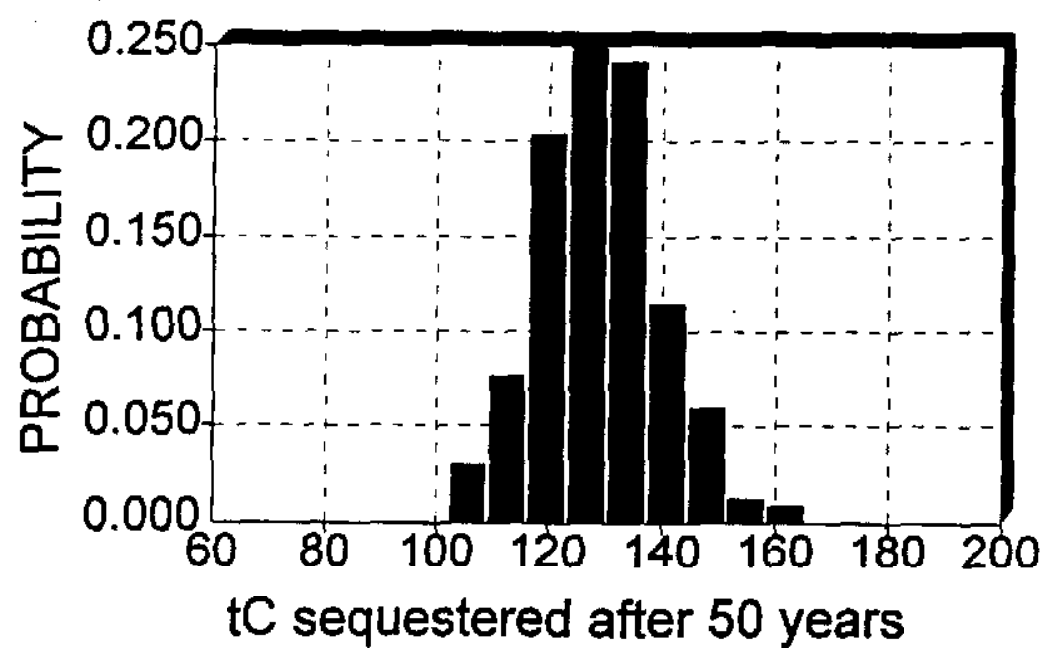

Figure 7: As in Figure 5, but with a smaller uncertainty of input parameters. 
A crediting scheme that discounted credits in proportion to their uncertainty would require careful balancing between the need for accurate measurement of carbon sinks and the cost of providing tbe required measurements. There appear to be two ways for projects to increase carbon credits for a project with uncertain outcome. One could either increase the project area or increase tbe accuracy with which key parameters are predicted and measured.

In summary, the Kyoto Protocol establishes the principle that removing carbon dioxide from the atmosphere is to be valued in tbe same way as is reducing emissions to the atmosphere. At the same time it creates many challenges on how these credits are to be measured and credited. We have yet to fully agree on what activities will produce credits, what pools will be c\&ted, who will receive credits, and how much credit will be available when there arc significant uncertainties in measurement.

\section{REFERENCES}

1 UNFCCC, 1997, Kyoto Protocol to the United Nations' Framework Convention on Climate Change, Document FCCC/CP/1997;7/Addl, at http://www.unfecc.de

2 UNFCCC, 1992, United Nations Framework Convention on Climate Change, see United Nations Environment Program, Information Unit for Conventions (IUC), http://www.unep.ch.

3 Schlamadinger, B., and G. Marland, 1996, The Role of Forest and Bioenergy Strategies in the Global Carbon Cycle, Biomass and Bioenergy 10: 275-300.

4 Marland, G., and B. Schlamadinger, 1997, Forests for Carbon Sequestration or Fossil Fuel Substitution? A Sensitivity Analysis, Biomass and Bioenergy 13:389-397.

5 Schlamadinger, B., and G. Marland, 1998, The Kyoto Protocol: Provisions and Unresolved Issues Relevant to Land-Use Change and Forestry, Environmental Science and Policy, in press.

6 Canada, 1998, in UNFCCC, Subsidiary Body for Scientific and Technological Advice, Report FCCC/SBSTA/1998/Misc.6/ADD1, Additional submissions by Parties, at http://www.unfccc.de

\section{NOTE 1:}

To produce Figures 4 and 5, we started with the scenario illustrated in Figure 2 and simulated how the model output might respond to uncertainty in the input parameters, We assumed that the probable growth rate of trees would be distributed according to a normal distribution, witb tbe mean given by the value used in Figure 2 and with a standard deviation of $16 \%$ of the mean. The harvest cycle length was taken to be distributed uniformly between 30 and 50 years (the discrete value in Figure 2 was 40 years). The efficiency with which fossil fuels are substituted (through the use of biofuels and through the displacement of energyintensive materials with wood) was treated as a triangular distribution with the extreme values equal to 50 and $150 \%$ of the mean value. A triangular distribution was also used for the lifetime of wood products, as well as for the share of waste wood used for energy. For these later parameters the lower and upper bounds were taken to be 0 and $200 \%$ of the mean. 